\title{
MicroRNA-210 contributes to peripheral nerve regeneration through promoting the proliferation and migration of Schwann cells
}

\author{
XIAONA ZHANG ${ }^{1}, \mathrm{XU} \mathrm{GONG}^{2}$, JINPENG QIU $^{1}$, YANG ZHANG $^{3}$ and FENGYAN GONG ${ }^{4}$ \\ Departments of ${ }^{1}$ Anesthesiology, ${ }^{2}$ Hand and Foot Surgery, ${ }^{3}$ Neurosurgery and ${ }^{4}$ Gynaecology and Obstetrics, \\ The First Hospital of Jilin University, Changchun, Jilin 130021, P.R. China
}

Received June 20, 2016; Accepted March 31, 2017

DOI: $10.3892 / \mathrm{etm} .2017 .4869$

\begin{abstract}
Peripheral nerve injury impacts the daily life of affected individuals. MicroRNA (miR)-210 is a multifunctional miR and has effects on the proliferation, migration and differentiation of cells. However, whether miR-210 has effects on peripheral nerve regeneration has remained elusive. In the present study, the miR-210 levels in a rat model of sciatic nerve injury were evaluated by reverse-transcription quantitative PCR and the effects of miR-210 on the proliferation and migration of Schwann cells were explored. Elevated miR-210 levels were discovered in the sciatic nerve injury rat model. miR-210 mimics were found to promote the proliferation and migration of Schwann cells, while miR-210 inhibitor was found to inhibit the proliferation and migration of Schwann cells. Further study showed that miR-210 had effects on the expression of growth-associated protein-43, myelin-associated glycoprotein and myelin basic protein. These results showed that miR-210 had effects on the proliferation and migration of Schwann cells and may be involved in the peripheral nerve regeneration.
\end{abstract}

\section{Introduction}

Injury to the peripheral nerves has an increasing incidence and results in nerve continuity interruption to impact the quality of life of affected individuals (1). In contrast to the central nervous system, the peripheral nervous system has

Correspondence to: Dr Xu Gong, Department of Hand and Foot Surgery, The First Hospital of Jilin University, 71 Xinmin Avenue, Changchun, Jilin 130021, P.R. China

E-mail: gongxu_gx@sina.com

Dr Jinpeng Qiu, Department of Anesthesiology, The First Hospital of Jilin University, 71 Xinmin Avenue, Changchun, Jilin 130021, P.R. China

E-mail: jinpeng_q@sina.com

Key words: miR-210, proliferation, migration, Schwann cells, sciatic nerve injury, peripheral nerve regeneration a regenerative capacity. In the peripheral nervous system, Schwann cells greatly contribute to the process of regeneration after nerve injury due to their de-differentiation (2). When peripheral nerve injury occurs, mature Schwann cells undergo phenotypic modulation, shedding the myelinsheath and de-differentiating to a progenitor state. De-differentiated Schwann cells may proliferate to replenish damaged tissues and produce a favorable environment for axonal to outgrow. Schwann cells also produce nerve growth factors, which are important for the survival and proliferation of axons $(3,4)$.

MicroRNAs (miRs) are a class of endogenous, small, non-coding RNAs. miRs regulate $>60 \%$ of the total human protein-coding genes at the post-transcriptional level and are involved in various biological processes, including cell proliferation, migration and differentiation as well as tumorigenesis (5). miRs also have important roles in nerve myelination. Previous studies reported that miRs are abnormally expressed after nerve injury and are involved in nerve regeneration (6-8). miR-9 is downregulated after sciatic nerve injury, and over-expression of miR-9 inhibited the migration of Schwann cells in vitro and in vivo (9). miR-34a and miR-140 are potential regulators of de-differentiation and proliferation of Schwann cells after peripheral nerve injury (8). In the absence of Dicer, which is crucial for the generation of mature miRs, Schwann cells undergo arrest at the pro-myelinating state and fail to myelinate axons $(10,11)$.

miR-210 is a multifunctional miR and is associated with proliferation, differentiation, mitochondrial metabolism and DNA damage repair (12). As a master hypoxamir (13), miR-210 is deregulated in numerous types of tumor and is associated with the development of tumors $(14,15)$. Studies have revealed that miR-210 is associated with poor survival of cancer patients (16) and is regarded as a potential biomarker of tumors (15,17-19). A recent study indicated that miR-210 also has effects on nerve cells (20). Administration of miR-210 is advantageous for the regeneration of the spinal cord (21). However, the effect of miR-210 on peripheral nerve regeneration remains unclear.

In the present study, the effects of miR-210 on the proliferation and migration of Schwann cells as well as proteins associated with nerve regeneration were explored. The results of the present study demonstrated that miR-210 had a beneficial 
effect on peripheral nerve regeneration and provided a novel approach for the treatment of peripheral nerve injury.

\section{Materials and methods}

Animal experimental protocol. A total of 60 male Sprague Dawley (SD) rats (8 weeks old; weight, 180-220 g) were supplied by Liaoning Changsheng Biotechnology Co., Ltd. (Benxi, China). The rats were fed in a standard condition (12-h light/dark cycle, $22^{\circ} \mathrm{C}, 45-55 \%$ humidity) with access to food and water ad libitum. Rats were randomly divided into 2 groups: The sciatic nerve injury group and the sham group. Rats in the sciatic nerve injury group were anaesthetized with $10 \%$ chloral hydrate (Sinopharm Group Co., Ltd., Shanghai, China; $3.5 \mathrm{ml} / \mathrm{kg}$; intraperitoneal injection). The sciatic nerve was exposed and lifted, and a $1 \mathrm{~cm}$-long sciatic nerve segment was resected. The incision site was treated with moderate penicillin powder (100,000 U; Harbin Motian Agricultural Technology Veterinary Drug Co., Ltd., Harbin, China) to avoid infection and then closed layer by layer. Rats in the sham group received the same operation, but the sciatic nerve was not resected. At $0,1,4,7,14$ days, a proportion of rats in each group were sacrificed, and the proximal stump of the sciatic nerve was harvested for subsequent reverse-transcription quantitative polymerase chain reaction (RT-qPCR). Animal experiments were approved by the Animal Ethics Committee of Jilin University (Changchun, China).

Isolation of Schwann cells. Schwann cells were isolated from sciatic nerves of 40-50 neonatal SD rats (Liaoning Changsheng Biotechnology Co., Ltd.; age, 1-3 days). The sciatic nerves were harvested and connective tissues on sciatic nerves were removed. The sciatic nerves were washed with PBS, cut into small pieces and digested in $0.125 \%$ trypsin (Beyotime Institute of Biotechnology, Beijing, China) and 0.2\% dispase for $25 \mathrm{~min}$ at room temperature. After centrifugation at $309 \mathrm{x} \mathrm{g}$ for $7 \mathrm{~min}$ at room temperature and washing with PBS, the cell pellet was re-suspended in Dulbecco's modified Eagle's medium (DMEM; Gibco; Thermo Fisher Scientific, Inc., Waltham, MA, USA) supplemented with $10 \%$ fetal bovine serum (FBS; Hyclone; GE Healthcare, Little Chalfont, UK) and seeded in plates. After incubation for an additional $24 \mathrm{~h}$, the cell medium was replaced for further culture. The isolated Schwann cells were grown in complete medium in a humidified atmosphere at $37^{\circ} \mathrm{C}$ with $5 \% \mathrm{CO}_{2}$.

Cell transfection. The isolated Schwann cells were seeded in 6-well plates at $1 \times 10^{6}$ cells per well. After $24 \mathrm{~h}$, an appropriate volume of lentivirus containing miR-210 mimics, negative control of mimics (mimics NC), miR-210 inhibitor or negative control of the inhibitor (inhibitor NC) (all from GenePharma, Shanghai, China) was added to the cells. A total of $6 \mu \mathrm{g} / \mathrm{ml}$ ploybrene (Sigma-Aldrich; Merck KGaA, Darmstadt, Germany) was added to each well to improve the transfection efficiency. After incubation with the lentivirus for an additional $24 \mathrm{~h}$, the cell medium was changed to fresh cell medium. The cells were then harvested for subsequent experiments.

MTT assay. At $24 \mathrm{~h}$ after transfection with miR-210 mimics, mimics NC, miR-210 inhibitor or inhibitor NC, Schwann cells were seeded in 96 -well plates at $4 \times 10^{3}$ cells per well. Cells were cultured for an additional $24 \mathrm{~h}$ and $5 \mathrm{mg} / \mathrm{ml}$ MTT (Sigma-Aldrich; Merck KGaA) was then added to each well. After incubation at $37^{\circ} \mathrm{C}$ for additional $4 \mathrm{~h}$, the supernatant was removed and $200 \mu$ l dimethyl sulfoxide (Sigma-Aldrich; Merck KGaA) was added to each well. The absorbance at $490 \mathrm{~nm}$ was measured using a microplate reader (BioTek, Winooski, VT, USA).

Wound healing assay. Cells were seeded into 6-well plates at $1 \times 10^{6}$ cells per well. When the confluence of cells was $80-90 \%$, scratches were made on the monolayer surface of cells using $200-\mu \mathrm{l}$ pipette tips. At $1 \mathrm{~h}$ prior to scratching, the cell medium was changed to serum-free medium and $1 \mu \mathrm{g} / \mathrm{ml}$ mitomycin C (Sigma-Aldrich; Merck KGaA) was added to each well. Subsequent to scratching, cells were washed with serum-free medium, and grown in serum-free medium in a cell incubator at $37^{\circ} \mathrm{C}$ with $5 \% \mathrm{CO}_{2}$. Images of cells in each group were captured at 0 and $24 \mathrm{~h}$. The relative mobility was calculated according to the gap size based on following formula: Relative mobility=1-gap size of the initial scratches/gap size of scratches at each time-point.

Transwell assay. Cells transfected with miR-210 mimics, mimics NC, miR-210 inhibitor or inhibitor NC were washed with PBS and re-suspended in serum-free medium. For each group, a total of $200 \mu \mathrm{l}$ cell suspension $\left(2 \times 10^{4}\right.$ cells) was added to the top chambers of the Transwell inserts (Corning, Inc., Corning, NY, USA). The lower chambers were filled with $800 \mu 1$ DMEM containing 20\% FBS. Cells were allowed to migrate for $24 \mathrm{~h}$ in a $37^{\circ} \mathrm{C}$ cell incubator. Subsequently, the Transwell membranes were washed with PBS and cells were fixed with $4 \%$ paraformaldehyde (Sinopharm Group Co., Ltd.). The upper surface of each membrane was cleaned with cotton swabs, and the bottom surface of each membrane was stained with $0.5 \%$ crystal violet (Amresco, Solon, OH, USA). Images of cells in each group were captured using an inverted microscope (Motic, Xiamen, China) under a magnification of $\mathrm{x} 200$. The number of cells that had transgressed through the microporous membranes was counted.

$R T-q P C R$. Total RNA was extracted from each sample using a total RNA extraction kit (BioTeke, Beijing, China) according to the manufacturer's protocol. The isolated total RNA was reverse-transcribed using a Super Moloney murine leukemia virus (M-MLV) reverse transcriptase (BioTeke). The reverse transcription mixture contained $1 \mu \mathrm{g}$ RNA, $1.2 \mu \mathrm{l}$ RT primer, $0.75 \mu \mathrm{l} \mathrm{dNTP}, 4 \mu \mathrm{l}$ 5x Buffer, $0.25 \mu 1$ RNasin, $0.2 \mu \mathrm{l}$ M-MLV, and $\mathrm{ddH}_{2} \mathrm{O}$ added up to $20 \mu \mathrm{l}$. The reaction conditions were as follows: $25^{\circ} \mathrm{C}$ for $10 \mathrm{~min}, 42^{\circ} \mathrm{C}$ for $50 \mathrm{~min}$, then $80^{\circ} \mathrm{C}$ for $5 \mathrm{~min}$. The reaction products were kept on ice. The miR-210 level in each sample was then detected by RT-qPCR (SYBR Green method). The RT-qPCR mixture contained $1 \mu 1$ reverse transcription products, $0.5 \mu \mathrm{l}$ forward primer, $0.5 \mu \mathrm{l}$ reverse primer, $10 \mu 1$ SYBR Green Mastermix (Beijing Solarbio Science and Technology Co., Ltd., Beijing, China), and $\mathrm{ddH}_{2} \mathrm{O}$ added up to $20 \mu \mathrm{l}$. The primers used were as follows: miR-210 forward, 5'-CATAGATAGCCACTGCCCACA-3' and reverse, 5'-GTGCAGGGTCCGAGGTATTC-3'; U6 small nuclear (sn) RNA forward, 5'-CTCGCTTCGGCAGCACA-3' and reverse, 
5'-AACGCTTCACGAATTTGCGT-3'. The cycling conditions were $95^{\circ} \mathrm{C}$ for $10 \mathrm{~min}, 40$ cycles of $95^{\circ} \mathrm{C}$ for $10 \mathrm{sec}, 60^{\circ} \mathrm{C}$ for $20 \mathrm{sec}$ and $72^{\circ} \mathrm{C}$ for $30 \mathrm{sec}$, followed by a final incubation at $4^{\circ} \mathrm{C}$ for $5 \mathrm{~min}$. The miR-210 level was normalized to U6 snRNA and the relative miR-210 level was calculated using the $2^{-\Delta \Delta C q}$ method (22).

Western blot analysis. Cells were harvested at $48 \mathrm{~h}$ after transfection with miR-210 mimics, mimics NC, miR-210 inhibitor or inhibitor NC. Protein in cells from each group was extracted using a protein extraction kit (Wanleibio, Shenyang, China). The protein concentration was measured using a bicinchoninic acid protein concentration detection kit (Wanleibio). Protein in each group was separated by $11 \%$ SDS-PAGE (40 $\mu \mathrm{g}$ per lane). The separated protein was transferred onto polyvinylidene fluoride membranes (Millipore, Bedford, MA, USA). The membranes were blocked with 5\% skimmed milk, followed by incubation with primary antibodies against growth-associated protein-43 (GAP-43; 1:200 dilution; Santa Cruz Biotechnologies, Inc., Dallas, TX, USA; cat. no. sc-33705), myelin-associated glycoprotein (MAG; 1:500 dilution; Bioss, Beijing, China; cat no. bs-0257R), myelin basic protein (MBP; 1:500 dilution; Bioss; cat. no. bs-0380R) and $\beta$-actin $\left(1: 1,000\right.$, Santa Cruz Biotechnologies, Inc.) at $4^{\circ} \mathrm{C}$ overnight. After washing with Tris-buffered saline containing Tween-20, the membranes were incubated with corresponding horseradish peroxidase-labeled secondary antibodies (1:5,000 dilution; Wanleibio; cat. nos. WLA023 and WLA024) at $37^{\circ} \mathrm{C}$ for $45 \mathrm{~min}$. The membranes were developed with an enhanced chemiluminescence detection system (Wanleibio). The optical density of target protein bands was analyzed using Gel-Pro-Analyzer 4.0 (Media Cybernetics, Inc., Rockville, $\mathrm{MD}, \mathrm{USA}$ ) and the relative protein levels were calculated using $\beta$-actin as an internal reference.

Statistical analysis. Experiments were repeated three times and values are expressed as the mean \pm standard deviation. Data analysis was performed using Student's t-test and one-way analysis of variance followed by Bonferroni's multiple comparison with GraphPad 5.0 (GraphPad Software, Inc., La Jolla, CA, USA). P $<0.05$ was considered to indicate a statistically significant difference.

\section{Results}

miR-210 is up-regulated in the proximal stump generated by sciatic nerve injury. Levels of miR-210 in the sciatic nerve injury rat models and the sham group were detected by RT-qPCR. The results revealed that in the sciatic nerve injury group, the level of miR-210 in proximal stump of the nerve was increased after sciatic nerve injury (Fig. 1). A significant upregulation of miR-210 occurred on day 1 after sciatic nerve injury and was highest on day 14 . However, in the sham group, the miR-210 levels at the same sites at which the stump was located in the model group showed no significant changes. These results demonstrated that miR-210 was upregulated after sciatic nerve injury.

miR-210 mimics promote the proliferation and migration of Schwann cells. After transfection with miR-210 mimics,

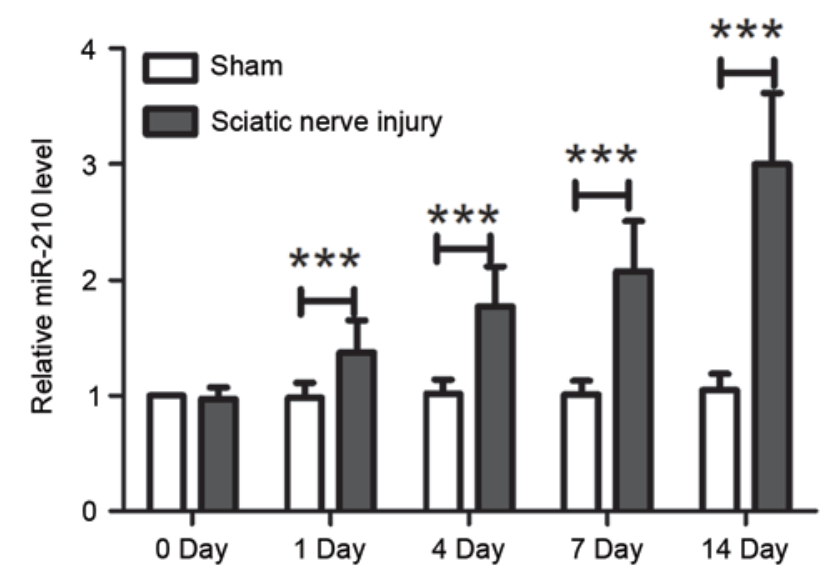

Figure 1. miR-210 levels in the proximal stump of the nerve. Levels of miR-210 in the sciatic nerve injury group and the sham group were detected by reverse-transcription quantitative polymerase chain reaction. The miR-210 level was normalized to U6 small nuclear RNA and the relative miR-210 level was calculated using the $2^{-\Delta \Delta C q}$ method. Values are expressed as the mean \pm standard deviation. ${ }^{* * *} \mathrm{P}<0.001$. miR, microRNA.

the miR-210 levels were detected by RT-qPCR. The results revealed that, after transfection with miR-210 mimics, the level of miR-210 was increased to $2.73 \pm 0.3$-fold of that in the mimics NC group (Fig. 2A). This result confirmed that miR-210 mimics effectively increased the level of miR-210.

After transfection with miR-210 mimics, the cell viability was detected by an MTT assay. As shown in Fig. 2B, after transfection with miR-210 mimics, the viability was significantly increased compared with that of cells transfected with mimics NC ( $\mathrm{P}<0.01$; Fig. 2B). This result showed that miR-210 mimics promoted the proliferation of Schwann cells.

The migration capacity of Schwann cells was determined by a wound healing assay and a Transwell assay. The results of the wound healing assay showed that the relative migration capacity of cells transfected with the mimics NC was $0.49 \pm 0.03$, whereas after transfection with miR-210 mimics, the relative migration capacity of cells was increased to $0.77 \pm 0.08$ ( $\mathrm{P}<0.01$; Fig. $2 \mathrm{C}$ and D). Consistent with the results of the wound healing assay, the Transwell assay also showed an enhanced migration capacity after transfection with miR-210 mimics. The number of cells transgressing through the microporous membranes was increased from $66.6 \pm 4.51$ to 109.4 \pm 10.95 ( $\mathrm{P}<0.001$; Fig. 2E and F). These results demonstrated that miR-210 mimics promoted the migratory capacity of Schwann cells.

miR-210 inhibitor reduces the proliferation and migration of Schwann cells. miR-210 inhibitor was used to downregulate the level of miR-210, and the miR-210 level was then assessed by RT-qPCR. The results revealed that after transfection with miR-210 inhibitor, the miR-210 level was decreased to $66 \pm 9 \%$ of that in the inhibitor NC group (Fig. 3A). This result demonstrated that miR-210 inhibitor effectively decreased the miR-210 level.

After transfection with miR-210 inhibitor, the cell viability was determined by an MTT assay. The results of the MTT assay showed that the cell viability was significantly suppressed after transfection with miR-210 inhibitor ( $\mathrm{P}<0.001$; Fig. 3B). 
A

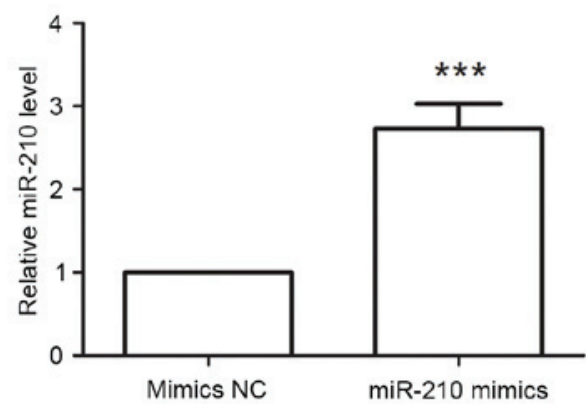

C
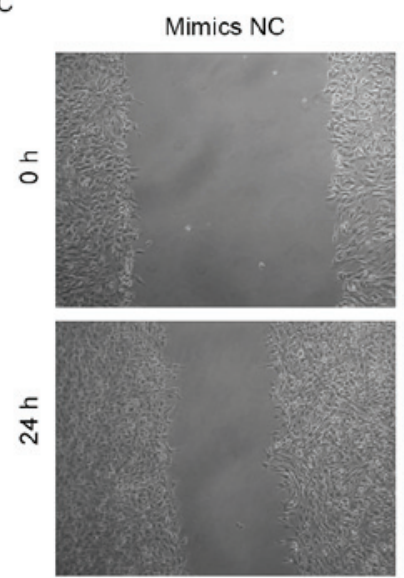

$\mathrm{E}$

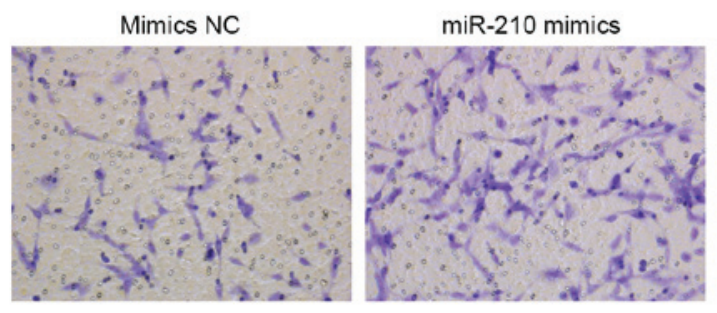

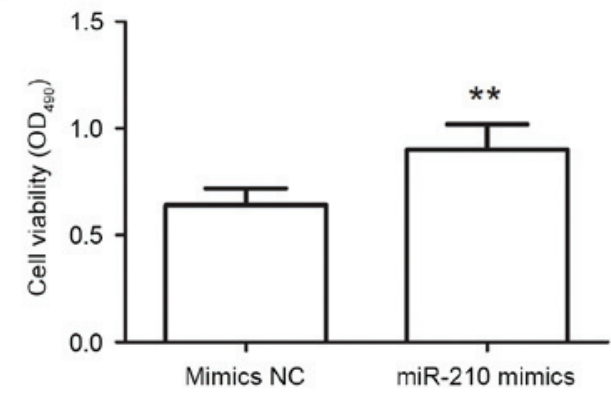
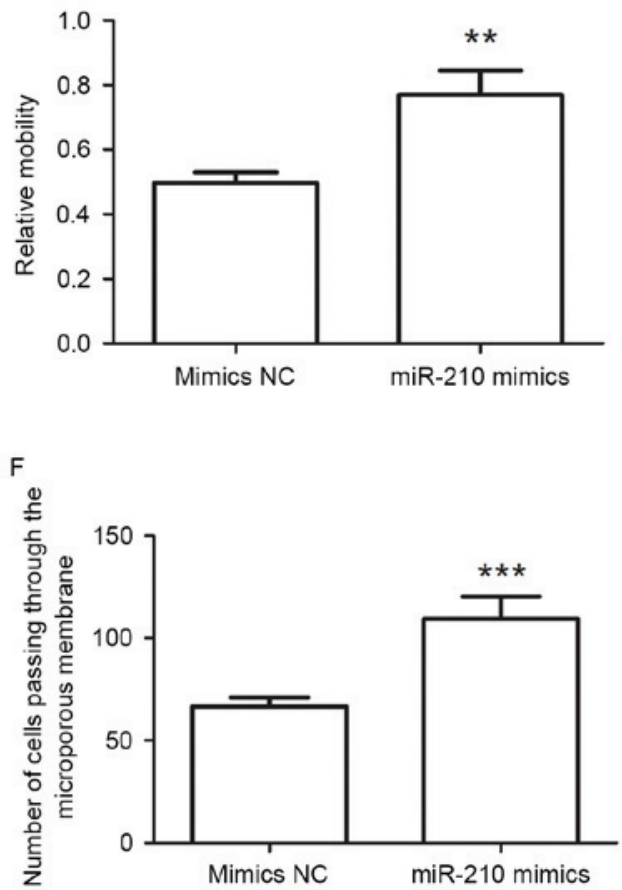

Figure 2. miR-210 mimics promote the proliferation and migration of Schwann cells. (A) The miR-210 level was detected by reverse-transcription quantitative polymerase chain reactionafter transfectionwith miR-210 mimics. (B) After transfection with miR-210 mimics, the viability of Schwann cells was detected by an MTT assay. (C and D) After transfection with miR-210 mimics, the migration capacity of Schwann cells was evaluated by a wound healing assay (magnification, x100). (E and F) After transfection with miR-210 mimics, the migration capacity was evaluated by a Transwell assay (magnification, x200). Each experiment was repeated three times and values are expressed as the mean \pm standard deviation. ${ }^{* *} \mathrm{P}<0.01,{ }^{* * *} \mathrm{P}<0.001$. miR, microRNA; NC, negative control; OD, optical density.

This result demonstrated that miR-210 inhibitor reduced the proliferation of Schwann cells.

The migratory capacity was also determined after transfection with miR-210 inhibitor. The results of the wound healing assay demonstrated that the relative migration capacity of Schwann cells was decreased from $0.54 \pm 0.03 \mathrm{in}$ the inhibitor $\mathrm{NC}$ group to $0.28 \pm 0.04$ in the inhibitor group (Fig. 3C and D). Furthermore, the results of the Transwell assay revealed that after transfection with miR-210 inhibitor, the number of cells transgressed through the microporous membranes was $34.8 \pm 3.56$, which was significantly lower than that of cells transfected with inhibitor $\mathrm{NC}(69.2 \pm 5.4 ; \mathrm{P}<0.001$; Fig. 3E and F). These results demonstrated that miR-210 inhibitor reduced the migration capacity of Schwann cells.

miR-210 regulates the protein levels of GAP-43, MAG and $M B P$. To further evaluate the effect of miR-210 on nerve regeneration, the protein levels of GAP-43, MAG and MBP were detected by western blot analysis. The results demonstrated that after transfection with miR-210 mimics, the relative protein levels of GAP-43 and MBP were increased to $2.7 \pm 0.3$ - and 1.85 \pm 0.19 -fold of those in the mimics NC group, while the relative protein levels of MAG were decreased to $47 \pm 8 \%$ (Fig. 4). After transfection with miR-210 inhibitor, the protein levels of GAP-43 and MBP were decreased to $47 \pm 7$ and $27 \pm 4 \%$ respectively, and the protein level of MAG was increased to $2.5 \pm 0.25$-fold of that in the inhibitor NC group (Fig. 4). These results demonstrated that miR-210 had a beneficial effect on nerve regeneration.

\section{Discussion}

In the present study, the effect of miR-210 on peripheral nerve regeneration was explored. The results revealed that 
A

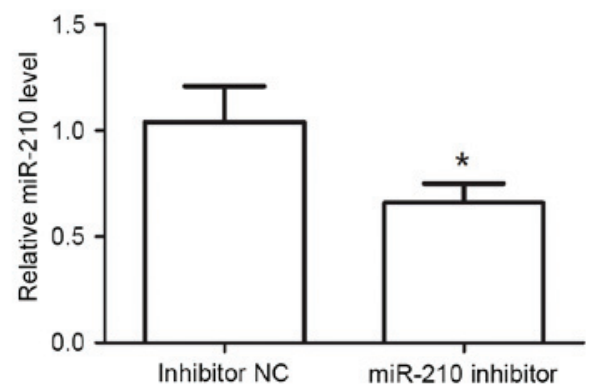

C
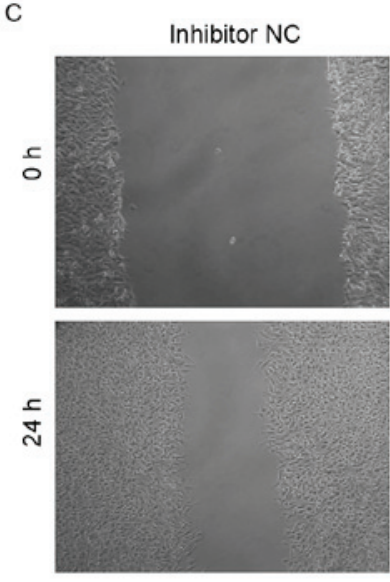

$E$

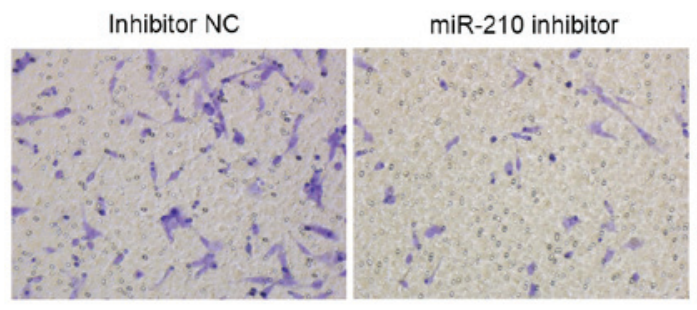

B

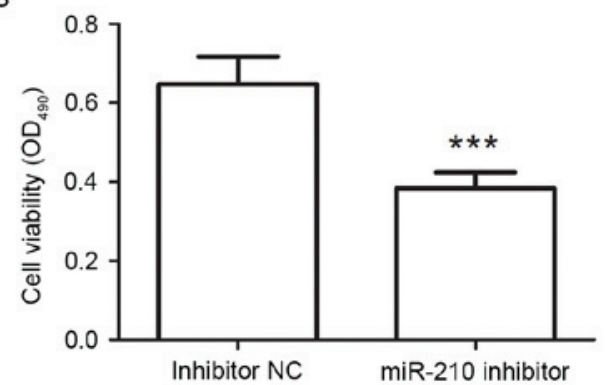

D
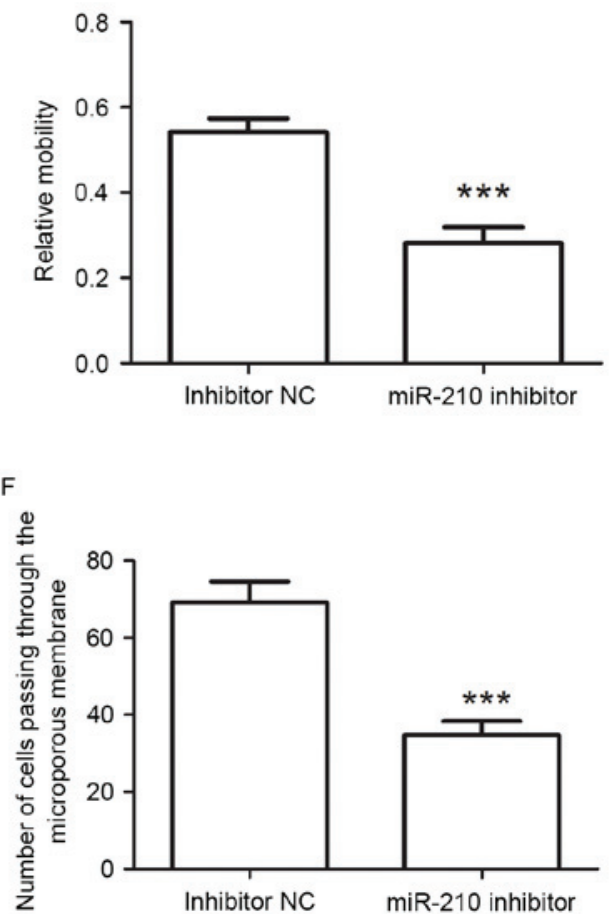

Figure 3. miR-210 inhibitor suppresses the proliferation and migration of Schwann cells. (A) Reverse-transcription quantitative polymerase chain reaction was used to detect the miR-210 level after transfection. (B) Cell viability of Schwann cells was measured by MTT assay after transfection with miR-210 inhibitor. (C and D) After transfection with miR-210 inhibitor, the migration capacity of Schwann cells was detected by a wound healing assay (magnification, x100). (E and F) A Transwell assay was used to evaluate the migration capacity of Schwann cells after transfection with miR-210 inhibitor (magnification, x200). All experiments were repeated three times. Values are expressed as the mean \pm standard deviation. ${ }^{*} \mathrm{P}<0.05,{ }^{* * * *} \mathrm{P}<0.001$. miR, microRNA; NC, negative control.

the level of miR-210 was increased after sciatic nerve injury. Further study showed that miR-210 mimics promoted the proliferation of Schwann cells and enhanced their migratory capability, while miR-210 inhibitor reduced the proliferation and migration of Schwann cells. miR-210 also impacted the protein expression of GAP-43, MAG and MBP. These results demonstrated miR-210 was beneficial for peripheral nerve regeneration.

Abnormal expression of miRs is associated with numerous diseases, such as cancer. After peripheral nerve injury, abnormal expression of miRs is usually discovered and is involved in peripheral nerve regeneration (6-9). In the present study, an increased miR-210 level was discovered after sciatic nerve injury. This led to the hypothesis that miR-210 may be beneficial to peripheral nerve regeneration. Studies have indicated that miR-210 has neuroprotective effects. It induces angiogenesis and neurogenesis, and inhibits apoptosis of neural progenitor cells (23-25), which is consistent with the hypothesis of the present study.
The present study found that miR-210 promoted the proliferation of Schwann cells, which indicates that miR-210 may be beneficial to the function of Schwann cells. miR-210 is usually regarded as an oncomiR. In most types of tumor, miR-210 promotes the proliferation of tumor cells. Through regulating E2F2 $(26,27)$ and YES1 $(28)$, miR-210 has effects on the cell cycle, thereby impacting the proliferation of cells. miR-210 also disturbs mitotic progression by targeting Polo-like kinase 1, cell division cycle 25B, Cyclin F, Bub1B and Fam83D (29). Apoptosis is another critical factor that impacts the proliferation of cells. B-cell lymphoma (Bcl)-2, which is an anti-apoptotic protein, is a target of miR-210. Through targeting Bcl-2, miR-210 may induce cell apoptosis (30). The effect of miR-210 on the proliferation of Schwann cells may be associated with the effect of miR-210 on cell cycle and apoptosis. A study by Wang et al (31) also showed that miR-210 promotes the proliferation of peripheral nerve sheath tumor cells, which was in line with the results of the present study. 
A

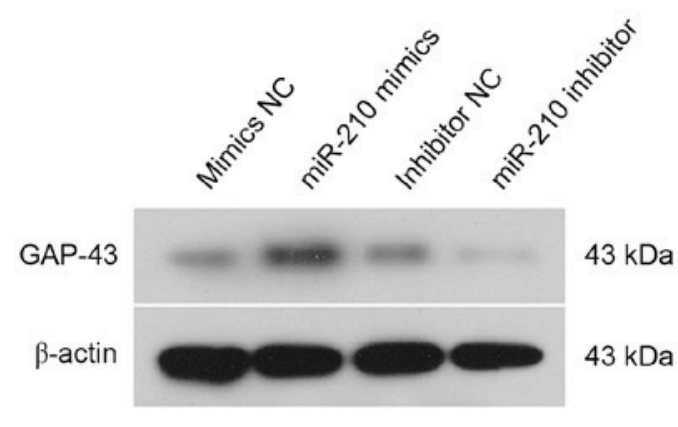

C

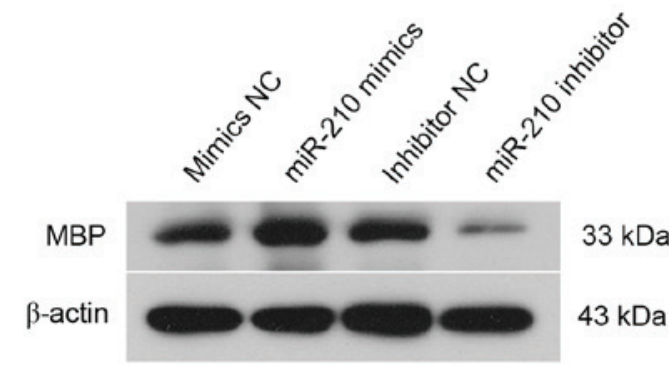

$\mathrm{E}$

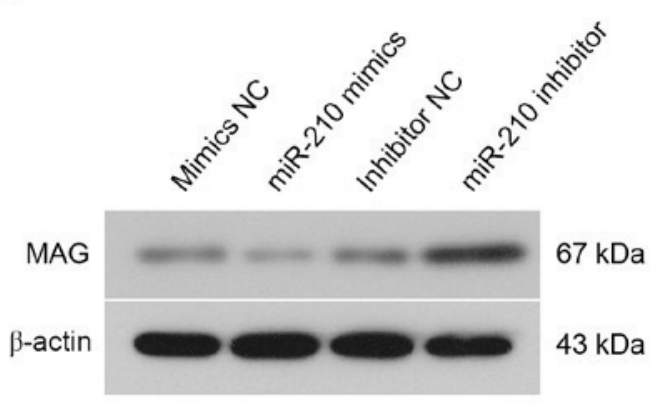

B

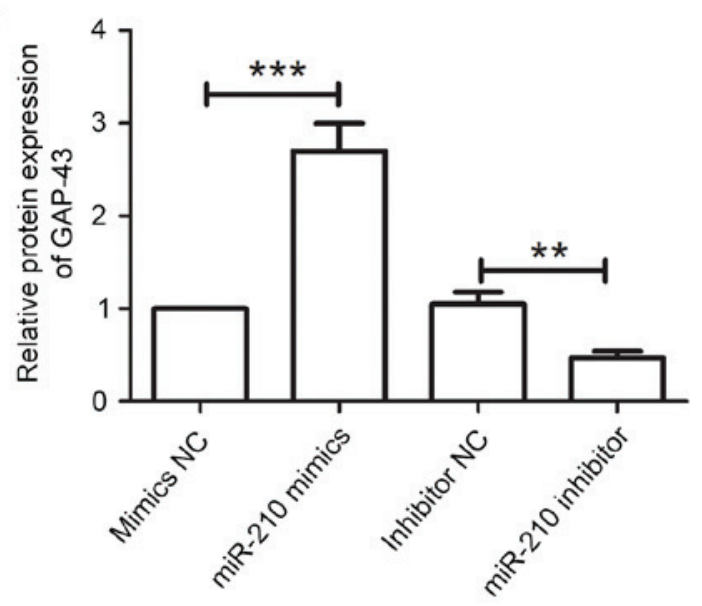

D

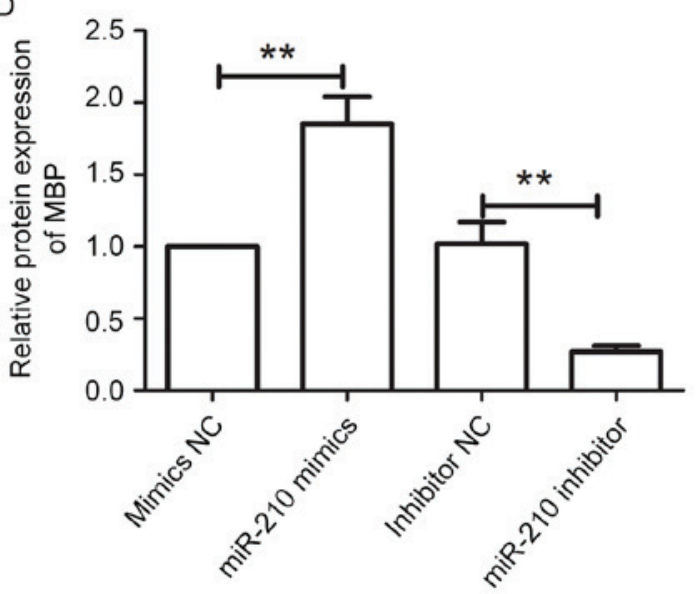

$\mathrm{F}$



Figure 4. miR-210 has an effect on the protein levels of GAP-43, MAG and MBP. (A and B) After transfection with miR-210 mimics or miR-210 inhibitor, the protein levels of GAP-43 were detected by western blot analysis. Relative protein levels were calculated using $\beta$-actin as an internal reference. (C and D) The protein levels of MBP were detected by western blot after transfection with miR-210 mimics or miR-210 inhibitor. $\beta$-actin was used as an internal reference. (E and F) After transfection with miR-210 mimics or miR-210 inhibitor, the protein levels of MAG were detected by western blot using $\beta$-actin as an internal reference. All experiments were repeated three times and values are expressed as the mean \pm standard deviation. ${ }^{* *} \mathrm{P}<0.01,{ }^{* * * *} \mathrm{P}<0.001$. miR, microRNA; MAG, myelin-associated glycoprotein; MBP, myelin basic protein; GAP-43, growth-associated protein 43; NC, negative control.

After peripheral nerve injury, Schwann cells dedifferentiate into an immature state. These immature, activated Schwann cells re-enter the cell cycle, migrate to the injury sites, secrete growth factors and promote axonal regeneration (32). In the present study, miR-210 was found to promote the migration of Schwann cells, which suggested that
miR-210 may be beneficial for Schwann cells to perform their functions. miR-210 has been reported to promote the migration of vascular endothelial cells and promote angiogenesis and neurogenesis (24). miR-210 is also associated with the migration of hepatocellular carcinoma, colorectal cancer and renal cell carcinoma (33-35). 
GAP-43 has important roles in the development and plasticity of the nerve. MBP is involved in myelination and maintaining the correct structure of myelin. In the present study, miR-210 was found to promote the expression of GAP-43 and MBP, indicating a beneficial role of miR-210 in peripheral nerve regeneration. MAG is also involved in myelination. However, in the present study, the protein levels of MAG were downregulated by miR-210. MAG is an axonal receptor ligand that is required for the maintenance of myelinated axons, as well as a receptor of axonal signals that promotes the differentiation and survival of oligodendrocytes. However, MAG is also a white matter inhibitor of neurite outgrowth and axonal regeneration. MAG inhibits the outgrowth of immature developing or regenerating neurites, and this is an aberration of its normal physiological function (36).

The present study found that the level of miR-210 was upregulated after sciatic nerve injury, which led to the hypothesis that miR-210 may be beneficial for peripheral nerve regeneration. Further study showed that miR-210 promoted the proliferation and migration of Schwann cells, which is advantageous for Schwann cells to perform their recovery role after peripheral nerve injury. The protein levels of GAP-43, MAG and MBP were found to be affected by miR-210, which further supported the hypothesis that miR-210 has a beneficial role in nerve regeneration. The present study demonstrated the role of miR-210 in peripheral nerve regeneration and provided additional evidence for the hypothesis that miRs have important roles in peripheral nerve regeneration. In addition, the present study provided novel insight into molecular mechanisms of nerve regeneration, which may provide a novel approach for the treatment of peripheral nerve injury.

\section{References}

1. Gu X, Ding F, Yang Y and Liu J: Construction of tissue engineered nerve grafts and their application in peripheral nerve regeneration. Prog Neurobiol 93: 204-230, 2011.

2. Webber $C$ and Zochodne D: The nerve regenerative microenvironment: Early behavior and partnership of axons and Schwann cells. Exp Neurol 223: 51-59, 2010.

3. Madduri S and Gander B: Schwann cell delivery of neurotrophic factors for peripheral nerve regeneration. J Peripher Nerv Syst 15: 93-103, 2010

4. Gupta R, Gray M, Chao T, Bear D, Modafferi E and Mozaffar T: Schwann cells upregulate vascular endothelial growth factor secondary to chronic nerve compression injury. Muscle Nerve 31: 452-460, 2005

5. Friedman RC, Farh KK, Burge CB and Bartel DP: Most mammalian mRNAs are conserved targets of microRNAs. Genome Res 19: 92-105, 2009.

6. Yu B, Zhou S, Wang Y, Ding G, Ding F and Gu X: Profile of microRNAs following rat sciatic nerve injury by deep sequencing: Implication for mechanisms of nerve regeneration. PLoS One 6: e24612, 2011.

7. Zhou S, Yu B, Qian T, Yao D, Wang Y, Ding F and Gu X: Early changes of microRNAs expression in the dorsal root ganglia following rat sciatic nerve transection. Neurosci Lett 494: 89-93, 2011.

8. Viader A, Chang LW, Fahrner T, Nagarajan R and Milbrandt J: MicroRNAs modulate Schwann cell response to nerve injury by reinforcing transcriptional silencing of dedifferentiation-related genes. J Neurosci 31: 17358-17369, 2011.

9. Zhou S, Gao R, Hu W, Qian T, Wang N, Ding G, Ding F, Yu B and Gu X: MiR-9 inhibits Schwann cell migration by targeting Cthrc1 following sciatic nerve injury. J Cell Sci 127: 967-976, 2014.
10. Pereira JA, Baumann R, Norrmén C, Somandin C, Miehe M, Jacob C, Lühmann T, Hall-Bozic H, Mantei N, Meijer D and Suter U: Dicer in Schwann cells is required for myelination and axonal integrity. J Neurosci 30: 6763-6775, 2010.

11. Yun B, Anderegg A, Menichella D, Wrabetz L, Feltri ML and Awatramani R: MicroRNA-deficient Schwann cells display congenital hypomyelination. J Neurosci 30: 7722-7728, 2010.

12. Devlin C, Greco S, Martelli F and Ivan M: miR-210: More than a silent player in hypoxia. IUBMB Life 63: 94-100, 2011.

13. Chan YC, Banerjee J, Choi SY and Sen CK: miR-210: The master hypoxamir. Microcirculation 19: 215-223, 2012.

14. Wang W, Qu A, Liu W, Liu Y, Zheng G, Du L, Zhang X, Yang Y, Wang $C$ and Chen $X$ : Circulating miR-210 as a diagnostic and prognostic biomarker for colorectal cancer. Eur J Cancer Care (Engl) 2016 (Epub ahead of print).

15. Lai NS, Wu DG, Fang XG, Lin YC, Chen SS, Li ZB and Xu SS: Serum microRNA-210 as a potential noninvasive biomarker for the diagnosis and prognosis of glioma. Br J Cancer 112: 1241-1246, 2015

16. Zhang Z, Wang J and Lü X: An integrated study of natural hydroxyapatite-induced osteogenic differentiation of mesenchymal stem cells using transcriptomics, proteomics and microRNA analyses. Biomed Mater 9: 045005, 2014.

17. Samaan S, Khella HW, Girgis A, Scorilas A, Lianidou E, Gabril M, Krylov SN, Jewett M, Bjarnason GA, El-said H and Yousef GM: miR-210 is a prognostic marker in clear cell renal cell carcinoma. J Mol Diagn 17: 136-144, 2015.

18. Iwamoto H, Kanda Y, Sejima T, Osaki M, Okada F and Takenaka A: Serum miR-210 as a potential biomarker of early clear cell renal cell carcinoma. Int J Oncol 44: 53-58, 2014.

19. Zhao A, Li G, Peoc'h M, Genin C and Gigante M: Serum miR-210 as a novel biomarker for molecular diagnosis of clear cell renal cell carcinoma. Exp Mol Pathol 94: 115-120, 2013.

20. Qiu J, Zhou XY, Zhou XG, Li Y, Cheng R and Liu HY: MicroRNA-210 knockdown contributes to apoptosis caused by oxygen glucose deprivation in PC12 cells. Mol Med Rep 11: 719-723, 2015.

21. Ujigo S, Kamei N, Hadoush H, Fujioka Y, Miyaki S, Nakasa T, Tanaka N, Nakanishi K, Eguchi A, Sunagawa T and Ochi M: Administration of microRNA-210 promotes spinal cord regeneration in mice. Spine (Phila Pa 1976) 39: 1099-1107, 2014

22. Livak KJ and Schmittgen TD: Analysis of relative gene expression data using real-time quantitative PCR and the 2(-Delta Delta C(T)) Method. Methods 25: 402-408, 2001.

23. Qiu J, Zhou XY, Zhou XG, Cheng R, Liu HY and Li Y: Neuroprotective effects of microRNA-210 against oxygen-glucose deprivation through inhibition of apoptosis in PC12 cells. Mol Med Rep 7: 1955-1959, 2013

24. Zeng L, He X, Wang Y, Tang Y, Zheng C, Cai H, Liu J, Wang Y, $\mathrm{Fu}$ Y and Yang GY: MicroRNA-210 overexpression induces angiogenesis and neurogenesis in the normal adult mouse brain. Gene Ther 21: 37-43, 2014.

25. Wang F, Xiong L, Huang X, Zhao T, Wu LY, Liu ZH, Ding X, Liu S, Wu Y, Zhao Y, et al: miR-210 suppresses BNIP3 to protect against the apoptosis of neural progenitor cells. Stem Cell Res 11: 657-667, 2013.

26. Giannakakis A, Sandaltzopoulos R, Greshock J, Liang S, Huang J, Hasegawa K, Li C, O'Brien-Jenkins A, Katsaros D, Weber BL, et al: miR-210 links hypoxia with cell cycle regulation and is deleted in human epithelial ovarian cancer. Cancer Biol Ther 7: 255-264, 2008.

27. Biswas S, Roy S, Banerjee J, Hussain SR, Khanna S, Meenakshisundaram G, Kuppusamy P, Friedman A and Sen CK: Hypoxia inducible microRNA 210 attenuates keratinocyte proliferation and impairs closure in a murine model of ischemic wounds. Proc Natl Acad Sci USA 107: 6976-6981, 2010

28. Tan W, Lim SG and Tan TM: Up-regulation of microRNA-210 inhibits proliferation of hepatocellular carcinoma cells by targeting YES1. World J Gastroenterol 21: 13030-13041, 2015.

29. He J, Wu J, Xu N, Xie W, Li M, Li J, Jiang Y, Yang BB and Zhang Y: MiR-210 disturbs mitotic progression through regulating a group of mitosis-related genes. Nucleic Acids Res 41: 498-508, 2013

30. Chio CC, Lin JW, Cheng HA, Chiu WT, Wang YH, Wang JJ, Hsing $\mathrm{CH}$ and Chen RM: MicroRNA-210 targets antiapoptotic Bcl-2 expression and mediates hypoxia-induced apoptosis of neuroblastoma cells. Arch Toxicol 87: 459-468, 2013.

31. Wang Z, Yin B, Wang B, Ma Z, Liu W and Lv G: MicroRNA-210 promotes proliferation and invasion of peripheral nerve sheath tumor cells targeting EFNA3. Oncol Res 21: 145-154, 2013. 
32. Heinen A, Lehmann HC and Küry P: Negative regulators of schwann cell differentiation-novel targets for peripheral nerve therapies? J Clin Immunol 33 (Suppl 1): S18-S26, 2013.

33. Ying Q, Liang L, Guo W, Zha R, Tian Q, Huang S, Yao J, Ding J, Bao M, Ge C, et al: Hypoxia-inducible microRNA-210 augments the metastatic potential of tumor cells by targeting vacuole membrane protein 1 in hepatocellular carcinoma. Hepatology 54: 2064-2075, 2011.

34. Qu A, Du L, Yang Y, Liu H, Li J, Wang L, Liu Y, Dong Z, Zhang X, Jiang X, et al: Hypoxia-inducible MiR-210 is an independent prognostic factor and contributes to metastasis in colorectal cancer. PLoS One 9: e90952, 2014.
35. Redova M,Poprach A, Besse A,Iliev R, Nekvindova J, Lakomy R, Radova L, Svoboda M, Dolezel J, Vyzula R and Slaby O: MiR-210 expression in tumor tissue and in vitro effects of its silencing in renal cell carcinoma. Tumour Biol 34: 481-491, 2013.

36. Quarles RH: A hypothesis about the relationship of myelin-associated glycoprotein's function in myelinated axons to its capacity to inhibit neurite outgrowth. Neurochem Res 34: 79-86, 2009. 